\title{
Collaborative E-Learning: Towards Designing an Innovative Architecture for an Educational Virtual Environment
}

\author{
Michael K. Badawy \\ Virginia Tech University \\ USA
}

\section{Introduction}

The digital age evolutionary advances have provided humankind with infinite educational opportunities. The greatest challenge to education in a global knowledge society is not how to effectively help learners acquire a well-defined set of knowledge and skills, but, rather, to help them learn how to work innovatively with ideas, and contribute to knowledge creation. Knowledge innovation in e-learning is a process where learners produce new perspectives, find new problem solutions, change the selections of existing knowledge structure and levels, and ultimately create new meaning via interaction and collaboration. A resulting central element is the emergence of new understanding of the original cognition. It follows that knowledge produced through analyzing, synthesizing, and appraising belongs to knowledge of innovation. As an educator, it is the author's conviction that one of the greatest contributions academics can make is to help students develop, and master the competency of "Learning How to Learn".

The utilization of collaborative virtual environments in e-learning is one of the most promising uses of virtual reality technology. Despite the existence of a vast literature covering e-learning system architectures, the author has found that most of the studies are focused on re-creating traditional education, and the use of new technologies serving traditional learning models- rather than an environment giving clear insights into the innovative knowledge generation and articulation. While considerable research has been undertaken in the area of networked virtual environments corresponding to sharing of events, very little research was done on specific services and functionality, (Montoya et al., 2011; Hamalmen, 2011).

In this chapter, e-learning is viewed as an educational paradigm referring to the utilization of web-based technologies to deliver learning activities with the aim of enhancing knowledge and performance. However, current e-learning efforts continue to put heavy emphasis on content delivery and technology (Lin et al. 2010; Chatti et al. 2007). This requires changes of orientation and focus from "content-driven" to "innovative knowledgedriven"; and from "technology-driven" to "learner-driven" e-learning models. This transformation requires creating an e-learning architecture based on knowledge innovation, while providing learners with an innovative learning environment.

This research focuses on exploring, understanding, and developing paths towards a viable framework for collaborative learning in dynamic group environments. Collaborative 
learning can be defined as a core mechanism embracing a variety of educational approaches to motivate learners to work closely in joint intellectual efforts. Hence, it refers to a situation where a joint solution to a problem is made synchronously and interactively. This means that dialogues will result between collaborating parties in the process of task engagement. This approach yields many positive benefits. This is due to that fact that interactions and deliberations among learners have remarkable beneficial impacts on their learning aptitude (Wolf et al. 2009). The central point here is that, in collaborative learning, participants engage in sharing information, brainstorming, and learning from each other. Therefore, their joint accomplishments would considerably exceed the sum of their individual contributions.

Based on the preceding discussion, the objectives of this chapter can be identified as follows:

- To pinpoint weaknesses in the existing e-learning systems while placing heavy emphasis on content delivery and technology, and explore how the transformation can be made from technology-driven to learner- driven models of e-learning.

- To present the design principles, features, primary aspects, elements, and strategic issues relating to building a collaborative e-learning environment.

- To explore the design and implementation of platforms suitable for educational virtual environments aiming at offering collaborative e-learning services to the users.

- To present a set of action strategies and critical success factors for educational developers to utilize in designing and implementing the proposed innovative architecture for enhancing educational virtual environments.

This chapter has been organized into eight sections. Following this introduction, Section 2 presents a detailed review of the literature providing a critique and an assessment of current e-learning systems. Conceptual definitions along with features of collaborative e-learning (CEL) are discussed in Section 3. Section 4 addresses the question of how the transformation from "Technology-Centric" to "Learner-Centric" models of CEL can be achieved. The design features, elements, and the strategic issues of CEL are discussed in Section 5. Section 6 describes a prototype as a guide towards designing an innovative architecture for an Educational Virtual Environment (EVE). This is accomplished through a presentation of the design principles for virtual spaces for CEL. A set of action strategies and critical success factors that can be utilized by educational developers in designing and implementing an innovative architecture for enhancing educational virtual environments are provided in Section 7. Finally, the conclusions, implications, and future research directions are presented in Section 8.

\section{Review of the literature: A critique and an assessment of current e-learning systems}

This section focuses on exploring the current status of e-learning systems based on the state of the art and the research literature. In addition, it contrasts "Education" with "Training"; and outlines current approaches to e-learning along with describing a wide range of applications. Finally, a critique and an assessment of e-learning systems are provided.

\subsection{Current status of e-learning systems}

The rate and speed with which technology development propagation is spreading globally is astounding. Technology permeates every aspect of our lives. The internet has profoundly revolutionized our world. It has increased global connections and competition to an 
unprecedented level. It has had the greatest impact through the availability of limitless easily accessible information. It is a barrier-free entry to global markets. In fact, it has radically changed the way we live and do business. Recent advances in technology have made learning and training accessible on "anywhere at any time" basis through distributed learning technologies. In such a short time, media literacy has evolved and was transformed into digital media literacy. One such example is how the e-learning approach to education is transforming the global educational system. Hence, e-learning can be defined as: the delivery of online digital education on demand to learners anywhere (Afie Badawy, 2009). The vast developments in internet and multimedia technologies are the basic enabler of e-learning with content, consulting, technologies, services, and support being identified as the five key sectors of the e-learning industry (Gierlowski et al. 2009; Nagy.et al; 2005).

Research shows that e-learning comprises all forms of electronically supported learning and teaching. The information and communication systems, whether networked or not, serve as specific media to implement the learning process (Tavangarian et al. 2004). The core point is that the internet, a non-proprietary system, is advancing the creation and delivery of engaging e-learning tools that transcend typical time and space barriers. E-learning is essentially the computer and network-enabled transfer of skills and knowledge. E-learning applications and processes include web-based learning, computer-based learning, virtual classroom opportunities, and digital collaboration. Content is delivered via the internet, intranet/extranet, audio or video tape, satellite TV, and CD-ROM. It can be self-paced or instructor-led and includes media in the form of text, image, animation, streaming video and audio.

E-learning tools refer to the internet-based programs designed for instructional purposes, such as interactive multimedia displays or threaded electronic messaging. Web-based collaborative environments are a special category of e-learning tools which support a group of learners in achieving a common learning goal. A central consideration here is to shift the focus to the question of: how did E-learning technologies emerge and evolve? Conventional e-learning systems were based on instructional packets which were delivered to students using assignments. Evaluations and assessments were undertaken by the instructor. Conversely, the new e-learning places increased emphasis on social learning and use of social software such as blogs, wikis, podcasts, and virtual worlds.

In contrast to the traditional paradigm, e-learning assumes that knowledge (as meaning and understanding) is socially constructed. It follows that learning takes place through conversations about content and grounded interaction about problems and actions. Advocates of social learning claim that one of the best ways to learn something is to try to teach it to others (Seely, et al. 2008). There is also an increased use of virtual classrooms (online presentations delivered live) as an online learning platform and classroom for a diverse set of education providers.

\subsection{Education vs. training}

Instructional providers along with other E-learning stakeholders in various organizations must now continue leveraging resources for designing and implementing learning and training strategies with the feature of sustained availability "any place any how" to meet the demand and expectations "anytime anywhere". An important issue in defining the domain and boundaries of e-learning is the necessity of differentiating between training and education. We should be cautious not to assume that what works well in education will necessarily work as well in training. While education and training share the psychological 
constructs of learning, memory, and motivation, fundamental differences exist. These differences relate to the goals, outcomes, and eventual application of the underlying instruction.

It is important to note that learning outcomes are measures of the knowledge gained from an instructional program. Education has been historically concerned with the social and intellectual development of the whole person; there is no upper limit to how elevated a learning outcome should be. A different way of framing the same issue is that while producing an "over educated" student is inconceivable to education providers, the thought of a student being "over trained" can be costly, in terms of time and money, to training providers. In short, it is better to have the prepared student productive on the job- rather than lingering in the classroom. It follows that while knowledge development is the intended outcome in education; skill development is the intended outcome in training.

\subsection{Approaches to e-learning}

Currently, there is a trend to move towards blended learning services where computerbased activities are integrated with practical or classroom-based situations. Research suggests (Kanev et al., 2009) that different types or forms of e-learning can be considered as a continuum ranging from no use of computers and/or the internet for teaching and learning, through classroom aids, such as making PowerPoint slides available to students through a course website or a learning management system, to laptop programs where students are required to bring and use their laptops as part of a face-to-face class, to hybrid learning, where classroom time is reduced but not eliminated, with more time devoted to on-line learning, which is a form of distance education. This classification refers to webenhanced, web- supplemented, and web- dependent to reflect increasing intensity of technology utilization. In the above continuum, "blended learning" can cover classroom aids, laptops and hybrid learning, while "distributed learning" can incorporate either hybrid or fully on-line learning.

The above discussion clearly shows that e-learning can describe a wide range of applications. A brief summary of these applications is presented below:

a. Computer-Based Learning (CBL): This refers to the use of computers as a key component of the educational environment. Although CBL can refer to the use of computers in a classroom, the term more broadly refers to a structured environment in which computers are used for teaching purposes.

b. Computer-Based Training (CBT): The term Web-based training (WBT) is often used interchangeably with CBT - the primary difference is the delivery method. While CBT is typically delivered via CD-ROM, WBT is delivered via the internet using a web browser. Note that CBT is a self-based learning activity accessible via a computer or handheld device. It typically presents content in a linear fashion- just like reading an online book or manual. This is why it is often used to teach static processes, such as using software or completing mathematical equations. One advantage is that assessing learning in a CBT usually comes in the form of multiple choice questions, or other assessments that can easily be scored by a computer such as drag-and-drop, radial button, simulation or other interactive means. Assessments are easily scored and recorded via online software, providing immediate end-user feedback and completion status.

Another advantage is that CBT provides learning incentives beyond traditional learning methodology from textbook, manual, or class-room based instruction. An example is 
that CBT offers visual learning benefits through animation or video as rich media that can easily be embedded for learning enhancement. A third advantage is that CBT can be easily distributed to a broad audience at a relatively low cost once the initial development is completed. However, CBT poses some learning challenges as well. One drawback is that the creation of effective CBTs requires enormous resources. Typically, the software for developing CBTs (such as Flash or Adobe Director) is often more complex than a subject matter expert or teacher is able to use. Additionally, the lack of human interaction can limit both the type of content that can be delivered, as well as the type of assessment that can be performed.

c. Computer-Supported Collaborative Learning (CSCL): Since collaborative learning is the main theme of this chapter, this e-learning modality will be explored in detail later on. It will suffice to assert that CSCL is one of the most promising innovations for improving teaching and learning using modern information and communication technology. While the most recent developments in CSCL have been called E-Learning, the concept of collaborative or group learning - whereby instructional methods are designed to encourage or require students to work together on learning tasks- has existed much longer. However, it is essential to distinguish collaborative learning from the traditional "direct transfer" model in which the instructor is assumed to be the primary provider of knowledge and skills.

d. Technology-Enhanced Learning (TEL): The field of TEL applies to the support of any learning activity utilizing technology. While the main concern relates to enhancing efficiency and cost effectiveness, the primary goal is to provide socio-technical innovations for e-learning practices- regarding individuals and organizations regardless of time, place, and pace.

\subsection{Shortcomings and weaknesses}

\subsubsection{The lack of project-based learning}

A broad examination of the literature reveals the weaknesses and shortcomings of current elearning systems (Bouras.et al, 2008; Law and Wong.2003; Monahan. et .al., 2008). There is also evidence that e-learning combines human resources, knowledge, technologies, tools so that learners can effectively hand quickly, accumulate, share, and create new knowledge. Knowledge innovations in e-learning lay their mark on the learning culture which is "learner-centered", project-based, and integrated (Michael Badawy, 2010). This is viewed as a more favorable process for learning and the development of new knowledge. In "projectbased" learning, learners take charge of their own learning, taking responsibility for personal understanding, and for the creation of knowledge artifacts. In this project context, the activities and methodologies of approaching projects are "shared "at a significant level among the learners. Therefore, learners can better promote knowledge when they address the spontaneous and creative forms that the collaborators use during the course of project completion. This means that the knowledge- creating activities and functions are not "controlled".

It is also noteworthy that the existing e-learning system has some inherent weaknesses including the absence of "project-based" learning; and a focus on knowledge acquisition. Additionally, while there is a vast literature about several e-learning system architectures, most of the studies focus on re-creating traditional school education, and the use of new technologies to serve traditional learning models - rather than an environment giving clear insights into the innovative knowledge generation and articulation(Montoya et al., 2011). 


\subsubsection{Current course and learning management systems are all asynchronous}

While current e-learning systems have improved with time, there are still some issues and challenges to be resolved before a truly stimulating and realistic learning experience can be provided on line. Through the use of technologies such as Virtual Reality (VR) and instant communication, students can be more virtually aware of their classmates, and can communicate in real time with them. They can also receive immediate feedback from their instructors, and gain a sense of being present with their peers despite their remote physical locations. These shared virtual environments also facilitate simultaneous viewing of learning materials by the entire class. It also allows them to actively participate in group discussions. Furthermore, the benefits of 3D graphics for education have been explored in the manufacturing industries, urban planning, entertainment, and military operations (Monahan.et.al. 2008; Lin et al; 2010; Montoya et al., 2011; Ryan et.al.2004; Manseur, 2005).

The core point here is that the use of VR and 3D graphics for e-learning has now been extended by the provision of entire VR environments where learning takes place. This highlights a shift in e-learning from the conventional text-based on line learning environment to a more immersive and intuitive one. Since VR is a computer simulation of a natural environment, interaction with a $3 \mathrm{D}$ model is more natural than browsing through 2D webpages looking for information (Monahan et al., 2008). These VR environments can support multiple users, further promoting the notion of collaborative learning where students learn together, and often from each other.

Course management tools, such as Blackboard and Scholar, Web Course Tools have been valuable in providing instructors with considerable help in facilitating the management of their online courses. These systems provide students with access to course materials and encourage them to participate in learning activities through the use of on line forums, discussion boards, and text-based chat. While these systems tend to be costly, systems with freely available source code have also been developed (Sung et al. 2009; Monahan et al., 2008). Moodle is such a learning system which is in widespread use. It offers a range of software modules that enable tutors to create on line courses. One area that it attempts to address is the need for pedagogical support. In particular, it promotes the notion of constructionist learning - where a student learns from her/his own experiences, resulting in a student-centered learning environment.

As noted earlier, most of the technologies along with communication methods utilized in current e-learning systems are all asynchronous, and therefore, students cannot receive instant feedback to queries or converse with their peers. This can create collaboration difficulties, and can cause feelings of remoteness for some users. Alternatively, synchronous technologies - such as text and audio communication- bring a real time element into communicating on line and can, therefore, enhance a user's online learning experience.

Specifically, they can help to increase a user's sense of belonging to a supportive learning community (Wolf et al., 2009; McInnerney et al.; 2004). It should also be noted that the presentation of learning content to users in an integrative, interesting, and inspiring manner have great value-added benefits. Text-based learning content often leads to boredom and can prevent students from gaining a clear understanding of the subject matter (Montoya et al., 2011; Lin et al., 2010; Zhang et al., 2004). The presentation of course content through multimedia techniques can be quite engaging to students in their learning activities. Multimedia can also increase their social presence by providing interactive and visually appealing 3D environments where learning and collaboration can take place. The computer often uses this kind of multimedia to create interactive and stimulating game environments, 
which give users a social presence and an opportunity to collaborate and communicate with others.

\subsubsection{The absence or lack of multi-user Virtual Reality (VR) technology}

Research shows that a variety of tools and technologies have been developed and used for supporting e-learning communities (Lin et al. 2010; Sung et al., 2009; Hamalamen, 2011; Bouras et.al., 2008). Three components and systems have been identified: the documentfocused web-based training tools; the meeting -focused tool (such as video-conferencing tools, Centra symposium...etc.) and the three dimensional (3D)-centered multi-user tools which are based on multi-user Virtual Reality (VR) technology. The first system focuses on the management of documents and on individual learning. The second system- the meeting focused tools-employs the approach of virtually representing the concept of frontal learningthat is the situation of a lecturer sending information to a group of learners, with rather little feedback, and almost no intended horizontal communication among learners. A general problem of these tools is the reduced social connection of the participants. Therefore, in such e-learning sessions, they experience a feeling of alienation.

The third system, VR tools, is focused on having participants experience a sense of interaction with and the existence of other participants. The participants of the 3D virtual session are represented by avatars, which can navigate through 3D environments. They are also able to view the actions of all other participants. In addition, Multi-user Virtual Reality technology tools, when utilized as communication media, offer advantages of creating social presence, thus, enhancing communication and interaction among participants. This is why multi-users of VR technology are used for supporting collaboration.

As noted earlier, current e-learning applications have many limitations that should be addressed and overcome. Essentially, some of the main limitations involve the lack of peer connection and interaction; and the need for flexible available tutorial support. Furthermore, the theoretical advantage of multi-user VR technology is not exploited in an extended manner. It mainly offers text chat communication, and users' representation through avatars. A good example is that advanced communication features, as voice or user gestures, are not commonly utilized.

\subsubsection{The need for shifting from "technology-centric and instructor-centric" to "learner-centric" paradigms with a strong focus on constructivism}

Recent research studies (Montoya et al., 2011; Wolf et al., 2009; Gierlowski et al., 2009; Kanev et al., 2009; Beetham, 2005) demonstrate that traditional educational instructor -centered approaches need to be replaced with more active instruction. Instead of viewing knowledge as an arbitrary set of facts, knowledge needs to be constructed by the learner so it can be used as a tool for future learning activities. There is an urgent need for shifting the focus of training and education from passive reception of facts to student knowledge transformation wherein an individual constructs new knowledge through interactions and negotiations.

It is essential to underscore the fact that constructivist principles include building on student prior knowledge, making learning relevant and meaningful, giving student's choice and autonomy, and having instructors act as co-learners. In this sense, instructors might design tasks wherein learners solve real world problems, reflect on skills used to manage one's own learning, address misconceptions in their thinking, categorize problems around themes and concepts, and generally take ownership for their own learning. 
A significant consideration in this regard is to note that there are two important variations of constructivism - cognitive constructivist and social constructivist. Cognitive constructivists tend to focus on the individual construction of knowledge discovered or built in interaction with the surrounding environment. From this point of view, it is important for educators to foster active learning environments in which learners can individually build knowledge. Essentially, the cognitive constructivist view regards knowledge as internally embodied in the mind of the learner. Unfortunately, individual notions of constructivism often fail to emphasize the dynamic social aspects of learning and cognition- the dialogue, collaboration, negotiation, and questioning of active learning environments.

Conversely, social constructivists view learning as connection with and appropriation from a larger social context. It follows that instructional methods from this latter view focus on dialogue, instructor co-learning, and the joint construction of knowledge. However, these essential features are lacking in the current e-learning paradigm.

As noted earlier, cognitive constructivists focus on making learning more relevant, building on student prior knowledge, and addressing misconceptions. Social constructivists, on the other hand, emphasize human dialogue, interaction, negotiation, and collaboration. It is important to note here that, across both perspectives, constructivist practices emphasize active, generative learning in which instructors continue to perform their critical learning function as learning guides. Note that the focus here is on "assisting learning", - not on "directing and assessing it".

The impact of using guided or assisted learning - instead of either mechanistic or discovery learning systems- fosters positive effects on learning. In an e-learning environment, such assistance might include questioning, task structuring, coaching, modeling, pushing students to articulate ideas and explore new avenues, and the occasional timely direct instruction. From a social constructivist viewpoint, new learning communities as a consequence can emerge. In summary, in an e-learning environment, the transformation from the current model of "instructor-centric" to "learner-centric" paradigm would have vast positive implications for students, instructors, and educational technology designers.

\section{Conceptual definitions and features of Collaborative E-Learning (CEL)}

\subsection{Definitions}

In the collaborative e- learning research literature, there is a broad acceptance of the meaning of CEL (Liang, 2010; Alfonseca et al., 2006; Kreijns et al. 2003; Dillenbourg, 1999). It has been defined as any kind of learning process performed by more than one person that takes place mainly in a Virtual Environment (VE). Another definition is that it is a situation in which two or more people learn or attempt to learn something together. While these definitions can be interpreted differently, the fact remains that they consist of three elements which define the space of what is encountered under the label "CEL": a group of individuals; attempting to learn something; in an interactive joint manner with an element of "togetherness".

As noted earlier, in order to provide e-learning services to the user, the components of the current systems of CEL can be divided up into three different tools: the document-focused web-based training tools; the meeting-focused tools; and the 3-D centered tools. We should keep in mind that several technology tools have accelerated the evolution of e-learning to a more collaborative and team-oriented mode. These tools include chat sessions, application sharing, virtual whiteboards, computer telephony, desktop videoconferencing, asynchronous 
communication, multi-user simulation environments, and audio graphics (Montoya et al., 2011; Alfonseca et al., 2006). Connections between all these essential elements point to the growing importance of collaboration, reflection, critical thinking, evaluation, and decisionmaking skills. Undoubtedly, as web technologies surge, skills in discovering, searching, integrating, filtering, and disseminating knowledge will gain more significance.

\subsection{Features}

The first step for implementing an effective functional e-learning virtual environment is to investigate its main functional features. These functional features should differentiate an elearning environment from other virtual environments which are designed and implemented for general use (Gierlowski et al., 2009; Bouras et.al, 2008, 2006). Research (Dillenbourg, 1999; Kanev et al. 2009) demonstrates that every virtual environment that integrates the following features can be characterized as a CEL environment:

- Users who have different roles and rights can visit the environment.

- The educational interactions in the environment should change the simple virtual space to communication space. Users should be provided with multiple communication channels, which enable them to interact with each other into the virtual space.

- The environment should be represented by various representation forms, which can range from simple text to 3D worlds.

- The learners in the environment should not be passive, but should be able to interact.

- The system that supports the e-learning environment should be able to integrate various technologies.

- The environment should support various e-learning scenarios.

- The environment should have common features with a physical space.

Another perspective on the CEL features relates to the debate in the literature concerning the differences and commonalities between "collaborative" and "cooperative" leaning. While joining this debate is beyond the scope of this chapter, this author believes that the similarities far outweigh the differences. These similarities have been well articulated by Kreijns et al, 2003, and Lin et al., 2010 which include:

- Learning is active

- The teacher is usually more a facilitator than a "sage on the stage"

- Teaching and learning are shared experiences

- Students participate in small group activities

- Students must take responsibility for learning

- Students are stimulated to reflect on their own assumptions, and thought processes

- Social and team skills are developed through the give-and-take of consensus building

\subsection{Why is virtual learning (VR) superior to traditional methods?}

There are many areas where VR has been used for supporting education (Sung et al., 2009; Bouras et al., 2008). These include : A. Simulation of complex systems, where the benefit compared to traditional methods is centered on the ability to observe system operations from a variety of perspectives, aided by superior quality visualization and interaction; B. Macroscopic and microscopic visualization, where the benefit compared to traditional methods is the observation of system features that would be either too small or too large to be seen on a normal scale system; and C. Fast and slow time simulation, where the benefit compared to traditional methods is the ability to control timescale in a dynamic event. 
Furthermore, compared to traditional methods, there are other significant characteristics of VR that could be leveraged for supporting education including the following (Laister, 2002; Bouras, et al. 2008; Redfern et al., 2002; Seely et al. 2008):

- High levels of interactivity that VR allows: Since most people learn faster by "doing", the VR system provides significantly higher levels of interactivity than other computerbased systems. Similarly, since the interfaces are intuitive and easy to use, the degree of interactivity could be very beneficial.

- Sense of immersion: This is a powerful characteristic, particularly in applications, where the sense of scale is quite important. A good example is that architecture is an area where the sense of scale is required for visualizing the impact of a building design on the external environment and the inhabitants.

- Inherent flexibility/adaptability: The flexibility of the VR system arises from the underlying software nature of the virtual environment. A VR system can be put to many uses by loading different application environments. This means that it is feasible to use a VR system for a wide range of learning applications.

Several propositions have been advanced by researchers relating to the usage of virtual environments in education (Hamalamen, 2011; Bouras et al., 2008; 2006). The following four propositions are germane to our discussion:

- Virtual environments create a feeling of presence by techniques, which shift attention from the real world to the virtual world.

- Virtual environments situate learning in a meaningful context. The environment's "landmarks" play a special role.

- Collaboration is possible and efficient in virtual environments. Moreover, users represented by avatars in the virtual world support the feeling of presence and the joy while learning.

- It is possible to learn by interacting with other students and virtual objects in virtual environments in a way similar to the interaction with real people and objects. This is why it is important to investigate the design principles that should be adopted by educational designers for effectively designing virtual spaces for e-learning.

\section{Achieving transformation from "technology-centric" to "learner-centric" models of CEL}

\subsection{Enhancing CEL through social interaction strategies}

Social interaction is a key to collaboration, and collaboration results in social interaction. If there is no social interaction, there would be no real collaboration. Research (Burleson et al., 2011; Kreijn et al., 2003; Beetham, 2005) shows that collaborative learning leads to a deeper level of learning, critical thinking, shared understanding, and long term retention of the learned material. It also provides opportunities for developing social and communication skills, developing positive attitudes towards co-members and learning material, and building social relationships, and group cohesion. These effects are strengthened further when collaborative learning is applied to ill- planned complex tasks embedded in an authentic context. Such conditions also increase the effectiveness of social construction of knowledge, and enable competencies' development.

However, there is agreement in the literature that placing students in groups does not guarantee collaboration (Montoya et al., 2011; Wolf et al., 2009). The incentive to collaborate 
has to be structured within the groups. A complex of simultaneously applied instructional approaches, reinforcing and/or complementing each other can actually enhance collaborative learning and social interactions among group members. These approaches can result in group members socially interacting in ways that encourage elaboration, questioning, rehearsal, and elicitation. For eliciting social interaction that would enhance collaborative learning, three approaches are proposed by Kreijns, et.al. 2003:

a. The cognitive approach: This approach is aimed at specific activities in the learning task that promote "epistemic fluency"-which is defined as the ability to identify and use different ways of knowing, to understand their different forms of expression and evaluation, and to take perspectives of others who are operating within a different epistemic framework (Morrison et.al. 1996). Note that epistemic fluency can be achieved by applying a set of epistemic tasks within the group learning tasks including describing, explaining, predicting, arguing, critiquing, evaluating, explicating, and defining - all in the context of a discourse.

b. The direct approach: This approach involves the use of specific collaborative techniques that structure a task specific learning activity- such as writing a report. Each specific collaborative technique can be used as a template for adaptation to a slightly different learning activity.

c. The conceptual approach: Centers around the notion of applying a set of conditions that enforce collaboration. It involves tailoring a general conceptual model of collaborative learning to the desired or chosen circumstances that specify the types of collaborate on to be created or enforced (Kreijns et al., 2003). However, conceptual methods cannot be easily learned, but can be used in any subject area, with any student groups, and are highly adaptable to changing conditions. The general dimensions and features of the conceptual approach are outlined below(Gierlowski et al., 2009; Zhou et al., 2008; Monahan et al., 2008; Kreijns et al. 2003; Johnson et al., 1999; Sharan et al., 1992; 1976)

- Positive interdependence: success can only be achieved through mutual dependency- a team member cannot succeed without other team members.

- Promotive interaction: Individuals encourage and help each other's efforts in order to achieve the group's goals.

- Individual accountability: all team members are held accountable for doing their share of the work, and for mastery of all the material to be learned.

- Interpersonal and small-group skills: Specific skills are needed when learners are learning within a group.

- Group processing: The group determines which behaviors should continue or change for maximizing success based upon reflection of how the group has performed so far.

\subsection{Understanding the foundations and principles of the "learner-centered" paradigm}

Fourteen learner-centered psychological principles were developed by The American Psychological Association (1993). These principles have extensive implications and considerable promise for the design of web-based instruction from a learner-centered angle. Based on the extensive research in the field of learning and development, studies address areas such as fostering curiosity and intrinsic motivation, thus, providing learners with choice and personal control, linking new information to old ones in meaningful ways, 
nurturing social interaction, promoting thinking and reasoning strategies, constructing meaning from information and experience, while considering learners' social and cultural background. These principles are necessary for a successful transformation from "Technology-Centric" to "Learner-Centric" paradigm. Such transformation requires designing a psychologically safe educational environment, electronic mentoring, facilitating learning, and other related tools and strategies.

Educational technologists and instructional designers are strongly advocating the critical need for shifting from instructor-centered to student-centered approaches. A learnercentered pedagogy centers around the notion that students must play an active role in the learning process: participating in determining what to learn, their learning preferences, and what is meaningful to them. The author strongly believes that one of the major benefits of the learner-centered "movement" is to make learning engaging for the learner.

As educators, we should take advantage of online tools in providing our students with opportunities to construct knowledge, actively share and seek information, generate a diverse array of ideas, appreciate multiple perspectives, take ownership in the learning process, engage in social interaction and dialogue, develop multiple modes of representation, and become more self-aware. The core point here is that technology- rich environments can support learner engagement in meaningful contexts, thus, increasing ownership over their own learning. For more information, guidance, and supporting research on learner-centered environments, the reader is referred to: (Hamalamen, 2011; Wolf et al. 2009; Oliver et al., 1999, Chung et.al.1998).

\subsection{Training instructors in learning and assuming new roles}

The different nature of online teaching calls for a significant change in the training and preparation of instructors to play new roles. Essentially, the role of the faculty member or instructor shifts to facilitator, coach, or mentor who provides leadership and guidance for enhancing student learning. Instructors have multiple roles they can assume on line. These include the roles of a chair, host, lecturer, tutor, facilitator, mediator, mentor, provocateur, observer, participant, co-learner, assistant, and community organizer. Research demonstrates that it might be important for the instructor to act as co-learner or participant in online activities. There is evidence suggesting that the on-line instructor must be flexible in constantly shifting between instructor, facilitator, and consultant roles (Wolf et al., 2009; Alfonseca et al., 2006). For facilitating online collaborative learning, it is also recommended that instructors be patient, flexible, responsive, and clear about expectations and norms for participation.

Research also suggests that categorizing the online acts of instructors into four categoriespedagogical, managerial, technical, and social - would be helpful in understanding the instructor's role in collaborative online environments (Peter et al., 2010; Kirkwood, 2010; Dalziel, 2003; Ashton, et.al.1999). Pedagogical action includes feedback, providing instructions, giving information, offering advice and preferences, summarizing or weaving student comments, and referring to outside resources and experts in the field. In short, the pedagogical role relates to direct instructor involvement in class activities. The second category - online managerial actions- involve overseeing task and course structuring. These include coordinating assignments, discussions, and the overall course organization and management. The third category - technical actions- relate to helping with user or system technology issues. Finally, social actions might include instructor empathy, interpersonal outreach (e.g. welcoming messages, invitations, etc.), discussion of one's own online 
experiences, and humor. An important research question, in this connection, would be to explore how different technologies and pedagogical strategies change the instructional interaction patterns and help promote community building.

In addition to understanding the roles instructors play, it is also important to reflect and contemplate the question: what do online instructors really do? Research (Peter et al., 2010; Kirkwood, 2010; Peffers et.al. 1999) reveals that online instructors tend to rely on simple tools such as e-mail, static or dynamic syllabi, Web links to course material, posting lecture notes on line, and accepting student work on line. However, most online instructors do not use online chat rooms, multimedia lectures, online examinations, animation, and video streaming. The core point here is that e-learning supports a more social constructive learning environment wherein students negotiate meaning, and are involved in extensive dialogue and interaction.

On the other hand, the role of the instructor, therefore, is in transition from director to facilitator or moderator of learning (Wolf et al., 2009; Selinger, 1999). Furthermore, electronic learners are more autonomous and independent in their own learning than their counterparts in traditional classrooms. E-learners also have greater opportunities for interacting with other learners, their instructor, and outside experts.

One approach to accelerating the transformation from technology-centric to learner-centric paradigm in CEL is to encourage educational technologists and instructional designers to undertake meaningful and credible empirical research explorations and evidence-based work to address three major questions: does CEL increase learning access?; Can it enhance the quality of learning?; and can this be done without additional cost? Clearly, these fundamental questions relate to the substantive dimensions of web-based instruction from the three important perspectives of efficiency, effectiveness, and cost-benefit analysis. Addressing these multi-dimensional issues would go a long way towards understanding the real "value-added" of online learning and its actual contributions.

\subsection{Identifying and addressing the pitfalls for social interaction in CEL}

There is ample empirical evidence suggesting that cognitive processes necessary for deep learning and information retention occur in dialogues (Van der Linden et al., 2001). However, research on group learning shows that asynchronous distributed learning groups utilizing computer-supported collaborative learning environments often lack the social interaction needed for these dialogues (Montoya et al., 2011; Wolf et al., 2009; Hallett et al, 1997). There are at least two identifiable factors which can be seen as pitfalls to social interaction:

\subsubsection{Taking social interaction for granted}

It is noteworthy that in a CEL environment, interaction does not just happen, but must be intentionally designed into the instruction. However, most educators take social interaction for granted. The fact remains that social interactions can no more be taken for granted in computer conferences than it can be in face-to-face settings as lecture halls or seminar settings. It follows that the first pitfall refers to taking for granted that social interaction will automatically occur just because technology permits it. Although CEL environments allow a certain degree of social interaction to take place, it is no more a matter of course than it is in face-to-face settings (Peter et al., 2010; Kirkwood, 2010). Therefore, it is prudent to conclude that just providing members of a distributed learning group with more communication 
media than they already have, neither necessarily fosters nor ensures social interaction. Put differently, availability of communication media is necessary- but not sufficient.

\subsubsection{Restricting social interaction to cognitive processes}

Research studies (Montoya et al., 2011; and Kreijns et al., 2003) suggest that educators recognizing the first pitfall often tend to limit their actions to the task context which is tightly related to the collaborative execution of learning tasks. In addition, they tend to limit their actions to the educational dimension -where social interaction is solely in service of the cognitive processes or other educational purposes. This, however, might not be enough. Moreover, research findings (Peter et al., 2010; and Kirkwood, 2010) emphasize the need for relationship building and sharing a sense of community and a common goal. Another research finding is that forming a sense of community, where people feel they will be treated sympathetically by their fellows, seems to be a necessary first step for collaborative learning. The fact remains that without a feeling of community, people are on their own, likely to be anxious, defensive, and unwilling to take the risks involved in learning.

It follows that the second pitfall relates to restricting social interaction to the cognitive processes in learning and ignoring or forgetting the importance of the social (psychological) dimension. This dimension concerns social interaction for group forming, group structure, and group dynamics - all of which are essential for building learning communities. This has been characterized in the literature as the "member support and group well-being functions"- which are so important for successful technology-mediated group-work. However, these group well- being functions are often neglected or worse yet, not even considered (Kirkwood, 2010; McConnell, 1994).

\section{Design features, primary aspects, elements, and strategic issues of collaborative e-learning}

The basic features of the educational virtual environment (EVE) were presented earlier. The balance of this chapter will focus on highlighting efforts geared towards designing an innovative architecture for an educational virtual environment. This discussion will center around three major interrelated issues. First, present the design features, elements, primary aspects, and strategic issues relating to collaborative e-learning environments. Second, discuss the design principles for virtual spaces for collaborative e-learning; Third, present a set of action strategies and critical success factors essential for effective implementation of the design principles, along with an assessment.

\subsection{Functional features and primary aspects of a Collaborative Virtual Environment (CVE)}

As noted earlier, exploring and investigating its primary functional features is the first step towards designing and implementing a functional and effective e-learning CVE. Several studies in the literature deal with various aspects of these complex issues (Kanev et al., 2009; Calongne, 2007; Bouras.etal.2008; Clark et al., 2006; Dillenbourg, 1999). These functional features should be specific enough in order to differentiate an e-learning environment from other virtual environments. Following Bouras et al. 2008, and Dourish et al. 1996, the design has to deal with some aspects of the "real world", which can be exploited by virtual spaces for collaboration and learning. The real world value of the features listed below is that they provide critical cues. These would allow individuals to organize their behavior accordingly. 
Every tool designed for supporting e-collaboration should exploit aspects of space and spatial mechanisms, such as providing identity, orientation, a locus for activity and a mode of control, which can be considered as powerful tools for the design.

CVE designers should include precise tools and take into account specific aspects in order to support the creation of places by the users who would, in turn, be able to create meaning of things in social interactions (Dourish, et al.; 1996; Clark et al. 2006; Bouras et al. 2008). These specific aspects are outlined below:

- Relational orientation and reciprocity: The spatial organization of the tools should be the same for all participants. The core point is that since people know that the world is physically structured for others in the same way as it is structured for them, they can use this understanding to orient their own behavior toward other people's use.

- Proximity and activity: More or less, people pick up objects that are near, not at a distance; they carry things to view them at close proximity which helps the learners/collaborators to be active and not passive in relating to activities and interacting with other learners.

- Partitioning: Resulting from the concept of proximity is the notion of partitioning. Since actions and interactions fall off with distance, this distance can be used for partitioning activities and the level of interaction.

- Presence, awareness, and support of users' representation: The sense of ongoing awareness of other people's presence and activity allows learners to structure their own activities, integrate communication and collaboration progressively, seamlessly, and easily. It should be noted that the use of avatars in a virtual environment is key for supporting collaborative e-learning. Additionally, note that the role of the lecturer as a facilitator is supported by the visualization of students represented as avatars in the virtual place (Wolf et al., 2009; Clark.et al.2006). Consequently, the visualization of students in a location helps the lecturer to gather students to specific locations - which provides a context for discourse in the virtual place. In short, it might be useful to represent the users by avatars that can support mimics and gestures, for supporting virtual and social presence, as well as for enhancing the ways of communication among the users with non-verbal communication.

\subsection{Fundamental design elements of a collaborative e-learning environment}

Research studies by Bouras et. al., 2008 and 2006; Dillenbourg, 1999; and Moshman, 1982 provide an insightful discussion and analysis of additional design elements focused on ecollaboration and e-learning. These are briefly presented below:

- Situated remote communication by supporting multiple communication channels such as avatar gestures, voice chat, and text chat.

- Remote task collaboration in distributed environments allows users to collaborate on tasks. This design element could be realized by:

a. Tools such as manipulation of shared objects, brainstorming board tool, locking/unlocking shared objects, user handling, as well as slide presentation and creation.

b. Supporting users who have different roles and rights when visiting the environment.

- Remote task support: Remote support by other learners, teachers, moderators, and participants. This design element could be realized by uploading material in the virtual space and data sharing. 
- Scaffolding tools: Tools such as whiteboard, brainstorming and slide creation can support collaborative scenarios as well as support the learners to undertake tasks in the virtual space. The whiteboard could support the learners in making presentations, while the brainstorming and slide creation could support the exchange and collection of ideas for assigned task.

- Representation of the environment by various representation forms, which can range from simple text to 3D worlds.

\subsection{Strategic issues for the design of a collaborative e-learning environment}

There are several issues that should be taken into account when using CVEs and developing CVEs in the future (Montoya et al., 2011; Liebregt, 2005, Bouras et al. 2008 and 2006). A brief statement of these issues is presented below:

- Instructors should be able to guide the learners.

- There are requirements for natural communication possibilities including realistic avatars and use of body language.

- It is essential to prevent the users from over-engagement with subtasks - not directly related to the main goal of the CVE.

- It is important to avoid frustration or distraction caused by unnecessarily complex interfaces

Further research problems of computer-mediated group learning could be summarized as follows (Montoya et al., 2011; Kirkwood, 2010; Hsi et al., 1997; Sweller, 1988):

- $\quad$ Reduced social presence-problem of social and cognitive orientation:

a. Group members tend to feel more as individuals than a group

b. The problem of "virtual group identity" leads to a depersonalization of group members

c. Low collaboration takes place

d. Reduced feeling of togetherness, group identity, and social presence

- Unnecessarily high amount of inessential load:

a. Split attention effect: separation of related information sources increase extraneous load

b. Poor use of working-memory capacity due to poor utilization of prior knowledge (rules and causal connections known from reality cannot be used)

The reader is referred to our previous discussion relating to the major pitfalls impeding achievement of the desired social interaction in collaborative e-learning environments.

\section{Design principles for virtual spaces for collaborative e-learning: Towards designing an innovative architecture for an Educational Virtual Environment (EVE)}

An inclusive set of eight very useful principles to support the design and implementation of desktop collaborative-learning environments were developed by Bouras, et al., 2008. These principles incorporated the resulting incremental developments and advancement of earlier findings and scenarios produced by other researchers such as Osborne, 1963; Aronson et al.; 1978; Lymna, 1981; Young, 1997; Johnson et al., 1998; Millis et al., 1998). A listing of the eight design principles along with a brief discussion are provided below:

Principle 1: Design to support multiple collaborative learning scenarios 
Principle 2: Design to maximize the flexibility within a virtual space

Principle 3: Augmenting user's representation and awareness

Principle 4: Design an inclusive, open, and user-centered virtual place

Principle 5: Design a media-learning centric virtual space

Principle 6: Ergonomic design of a virtual place accessible by large audience

Principle 7: Design to reduce the amount of extraneous load of the users

Principle 8: Design a place for many people with different roles

Multiple collaborative tools are designed to support the execution of the different e-learning scenarios such as: brainstorming, roundtable, jigsaw, think pair share, quick-writes, and micro-themes...etc. It is important to recognize that e-learning environments can support many groups of users in a variety of subjects. This means that some scenarios would fit better in certain subjects than in others, for this reason users/instructors should be provided with the capability to choose among various scenarios. Additionally, due to the need for multi-functionality within a collaborative on-line synchronous session, it should be made easy, simple and quick to re-organize the virtual place for a particular activity or scenario. One simple approach is to increase the level of flexibility and divide the virtual environment into smaller areas. Such division would allow for ease of undertaking the specific functions. However, despite its benefits, this approach can result in disorientation and rise of the cognitive load of the users concerning the virtual space operation.

Augmenting the user's representation and awareness underscores the importance of combining gestures, mimics; user representation, audio, video and text chat communication, as well as application sharing, similarly, the virtual objects and media can be integrated. All these key elements would provide users with the capability to share their views with others, and show the objects they are discussing. Awareness of other people and objects is essential for e-learning and helps in focusing on the visualization of others, and the representation of their actions on the objects discussed. But, in order to support as many users as possible, a collaborative virtual space should be accessible as much as possible, and access should remain open and not restricted. Open access is important to guide the moderators, instructors, and the individuals responsible for it. In addition, each part of the technology implementation processes would have to guarantee the continuation and general implementation of the specific technology utilized.

Furthermore, in designing media-learning centric virtual spaces, several guidelines for implementation would have to be followed. Virtual environments require multiple communication channels to be based on the differing needs, and requirements. Many communication channels such as application sharing, message board, voice chat, text chat, etc. should be integrated in the virtual space in order to enhance communication awareness among users. While communication should not be intrusive, users should be able to utilize the right channel for the right task. Equally important is the need for virtual environments to be easily accessible. Furthermore, access to the virtual environment should be user friendly; fast and simple in terms of registration, software download and installation.

It should also be emphasized that reducing the amount of unnecessary load is a very important design principle. The commands of interfaces should be in a graphical user interface fashion, and all functions and tools should be located in the same window. Since the main objective of an e-learning environment is to support the learning process, the operation of the learning environment should be simplified and user friendly. Another key consideration concerns the design of a virtual environment according to the needs of the individual roles. Access tools to support a variety of roles with differing access rights are 
necessary. Such tools and access rights would support the participant's different roles such as regulating interaction by moderators or instructors, however, these tools may not be available to learners.

\section{Action strategies and critical success factors: Implementation of the principles}

\subsection{Implementation issues}

Extensive accounts of the tools and mechanisms for implementation of the design principles discussed above are provided in detail in the literature (Montoya et al., 2011; Lin et al. 2010; Jarczyk, 1992; Bouras et al.2008; 2006; 2005;2002). These principles could be implemented in 3D collaborative virtual environments in order to support collaborative e-learning communities. Bouras and his co-authors demonstrated how the principles can be applied using the Educational Virtual Environment (EVE) Training Area tool. This tool can be described as a three-dimensional space where participants - represented by 3D humanoid avatars- can use a variety of e-collaboration tools. In some cases, other tools are used in order to demonstrate different implementations and design approaches.

As discussed earlier, current research on the design of collaborative e-learning virtual environments identified various issues and aspects of such environments. The eight-principles presented above would help designers in creating virtual spaces focused on supporting collaborative e-learning. Despite the usefulness of these design principles, the core question still remains: What is the best practice for transforming them into modeling concepts and specific concrete functional features? It is important to note that in the case of EVE, the first step was to investigate the main functional features. As demonstrated by Bouras et al., 2006, the next step was to create a prototype- which was evaluated by users.

It is not only difficult, but may also be restrictive for educational designers to follow a set of rules for transforming the design principles to functional features. The central issue here is the large set of parameters that need to be taken into account. This includes collaborative elearning techniques that will be used, user requirements, users' profile, etc. A possible solution to that issue is to use these principles as a guide during a "Design Rationale" process of software engineering. In its simplest, a design rationale is the explicit listing of decisions made during a design process, and the reasons why those decisions were made (Peter et al., 2010; Dalziel, 2003; Ravenscroft et al., 2002; Jarczyk et al., 1992). In short, these principles could be used as criteria to review and select a 3D CVE platform for supporting collaborative e-learning scenarios.

\subsection{Evaluation}

A usability evaluation of the prototype was undertaken by Bouras, et al. 2006 in order to validate the design of EVE prototype. Research studies (Montoya et al., 2011; Lin et al., 2010; Kirkwood, 2010; Peter et al., 2010; Bouras et al. 2008 and 2006; Dalziel, 2003) suggest that the objectives of the usability evaluation are to: (a) assess usability problems with the EVE interface, and (b) investigate more requirements of the end users in order to improve the functionality of the EVE prototype. These studies report that the general impressions by most of the end users participating in the research were positive.

The concept of EVE prototype has been rated as a promising solution for collaborative elearning. It was felt that the 3D metaphor of a virtual classroom is a useful approach to support synchronous e-learning, particularly for small groups of learners. Moreover, the 
simplification of the user interface using 3D metaphors, the support of different file formats, and the use of audio communication channel are the main factors for the general acceptance. Furthermore, the ease of the user interface utilization of the prototype has been rated as positive. The users indicated that they got along well with the system. However, they stated that the interface of the 2D tools need improvement (e.g., the buttons for the avatar gestures should be replaced by icons). This is in addition to the need for improving the error tolerance of the system.

\section{Summary, conclusion, implications, and future research directions}

The focus of this chapter has been on exploring and offering a comprehensive paradigm and a conceptual architecture for collaborative e-learning for an educational virtual environment. As a point of departure, the author has started out by portraying the current status of e-learning systems, explaining the evolving role and vision of e-learning. A thorough review of the literature painting a profile of the state of the art has been provided. It has been presented with an eye towards highlighting various approaches to e-learning, along with a critique and an assessment of their shortcomings and weaknesses. This research has revealed that the core weaknesses of current e-learning systems revolve around four major dimensions. These include the lack of project-based learning; current course and learning management systems are all asynchronous; the lack of a multi-user VR technology; and the need for shifting from "technology-centric and instructor-centric" to "learnercentric" paradigms with a strong focus on constructivism.

CEL has been defined as any kind of learning process performed by more than one individual that takes place mainly in a virtual environment. This research helps advance our knowledge and accelerate our understanding of the dynamics of CEL in several ways. First, the criteria, benchmarks, and features of a CEL environment have been refined along with the reasons why VR has been used for supporting education. Second, this research has led to the conclusion that there are significant characteristics of VR which could be leveraged for supporting education. These characteristics along with several research propositions germane to our discussion were examined. Third, a detailed account has been provided representing a pathway consisting of several strategies and mechanisms essential for achieving transformation from "technology-centric" to "learner-centric models of collaborative e-learning". These mechanisms include the critical need for enhancing collaborative e-learning through social interaction strategies; understanding the foundations and principles of the "learner-centered" paradigm; training instructors in learning and assuming new roles; and the necessity for identifying and addressing the pitfalls for social interaction in collaborative e-learning.

Fourth, exploring and investigating CEL primary functional features is the first step towards designing and implementing an effective e-learning collaborative virtual environment. These functional features should be specific enough in order to differentiate an e-learning environment from other virtual environments. The functional features and primary aspects of a collaborative virtual environment have also been presented, along with the fundamental design elements, and the strategic issues to be taken into account in developing collaborative virtual environments in the future. Fifth, a well-designed set of principles for virtual spaces for collaborative e-learning were discussed. Finally, some action strategies and critical success factors concerning the implementation of the design principles have been presented. 
Taken collectively, in line with the overall theme of this chapter - crystalizing the multiple dimensions of collaborative e-learning - the path leading towards designing an innovative architecture for an educational virtual environment has been identified.

This research has a number of important implications- which have been discussed throughout the chapter, and thus, there is no need for repeating them here.

This chapter raises a number of research questions and issues to be addressed by scholars and students interested in further exploration of collaborative e-learning. Some of these questions are presented below in a seven-item future research agenda:

- To what extent does collaborative e-learning increase learning access? (efficiency)

- To what extent does it enhance the quality of learning? (effectiveness)

- Are the benefits cost effective? And how can we measure them? (cost-benefit analysis)

- How does collaborative e-learning compare to other technologies in the area of networked virtual dynamic group environments in terms of functionality, outcomes, and administration?

- In addition to the mechanisms and protocols proposed in this chapter, how can social interaction be further enhanced?

- Apart from the methods and protocols presented in this chapter, how can educational designers go about transforming the proposed set of design principles into modeling concepts and specific concrete functional features?

- How would different technologies and pedagogical strategies change the instructional interaction patterns and help promote community building?

\section{References}

Alfonseca, E.; Martin, E.; Paredes, P.; Carro, R.; Ortigosa, A. (2006). The Impact of Learning Styles on Student Groupings for Collaborative Learning: A Case Study. User Model User- Adap Inter, Vol. 16, pp.377-401.

American Psychological Association. (1993). Learner-Centered Psychological Principles: Guidelines for School Reform and Re-structuring. Washington, DC: American Psychological Association and the Mid-Continent Regioal Educational Laboratory.

Aronson, E.; Blaney, N.; Stephan, C.; Sikes, J.; Snapp, M. (1978). The Jigsaw Classroom. Sage Publications.

Ashton, S.; Roberts, T.; Teles, L. (1999). Investigation of the Role of the Instructor in collaborative online environments. Session presented at the CSCL '99 Conference, Stanford University, CA.

Badawy, Afie (2009). Technology Management Simply Defined: A Tweet Plus Two Characters. Journal of Engineering and Technology Management, Volume 26, Issue 4, December, Pages 219-224.

Badawy, Michael K. (2010). A Research Architecture for Technology Management Education. In H. Bidgoli (Ed.) The Handbook of Technology Management, Core Concepts, Financial Tools and Techniques, Operations and Innovation Management. Vol.1, pp. 3-18. New York: Wiley.

Beetham, H. (2005). E-Learning Research: Emerging Issues?. Research in Learning Technology, Vol. 13, No.1, (March 2005), pp. 81-89. 
Bouras, Ch.; Giannaka, E. (2008). Exploiting Virtual Environments to Support Collaborative E-Learning Communities. International Journal of Web-Based Learning and Teaching Technologies, Vol.3. No.2, (April-June 2008), pp.1-22.

Bouras, C.; Tsiatsos, T. (2006). Educational Virtual Environments: Design Rationale and Architecture. Multimedia Tools and Applications, Vol. 29, No.2, pp. 153-173.

Bouras, C.; Tsiatsos, T. (2002). Extending the Limits of CVE to Support Collaborative ELeaening Scenarios. @nd IEEE International Conference on Advanced Leaening Technologies, Kazan, Russia, September 2002, pp. 420-424

Burleson, W.; Tripathi, P. (2011). Mining Creativity Research to Inform Design Rationale in Open Source Communities. In Human Technology: An Interdisciplinary Journal of Humans in ICT Environments on Creativity and Rationale in Software Design. Agora Center, University of Jyvaskyla.

Calongne, C. (2007). A View from Second Life's Trenches: Are You a Pioneer or a Settler?. Proceedings of the NMC Summer conference, 2007, pp.111-119.

Chatti, M.; Klamma, R.; Jarke, M.; Naeve, A. (2007).The Web 2.0 Driven SECI Model Based Learning Process. Seventh IEEE International Conference on Advanced Learning Technologies, Niigata, pp. 780-782.

Chung, H.; Rodes, P.; Knapczyk, D. (1998). Using Web Conferencing to Promote Ownership in Distance Education coursework, Proceedings of the WebNet 98 World Conference of the WWW, Orlando, Florida, No.IR019242.

Clark,S.; Maher, M. (2006). Collaborative Learning in 3D Virtual Place: Investigating the Role of Place in a Virtual Learning Environment. Journal of Science Education and Technology, Vol. 8, No.1,pp18-31.

Dalziel, J. (2003). Implementing Learning Design: The Learning Activity Management System (LAMS), Unpublished Manuscript,

Dillenbourg, P. (1999). What Do You Mean by Collaborative Learning?. In Dillenbourg (Ed). Collaborative :Cognitive and Computational Approaches. Elsevier, Oxford, pp. 119

Dourish, P.; Harrison, S. (1996). Re-Placing Space: The Roles of Place and Space in Collaborative Systems. Proceedings of the ACM Conference on Computer Supported Cooperative Work, pp. 68-85.

Gierlowski, K.; Nowicki, K. (2009). A Novel Architecture for E-Learning Knowledge Assessment Systems. International Journal of Distance Education Technologies, Vol.7, Issue 2, pp. 1-19.

Hallet, K.; Cummings, J. (1997). The Virtual Classroom as Authentic Experience. In Proceedings of The vAnnual Conference on Distance Teaching and Learning, pp.103-107. Madison, Wisconsin: University of Wisconsin-Madison.

Hamalamen, R. (2011). Using a Game Environment to Foster Collaborative Learning: A Design-Based Study. Technology, Pedagogy and Education,Vol.20, No.1, (March 2011, pp. 61-78.

His, S.; Hoadley,C. (1997). Productive Discussion in Science; Gender Equity through Electronic Discourse. Journal of Science Education and Technology, Vo.6, No.1.

Jarczyk, A, Loffler, P.; Shipman, F. (1992). Design Rationale for Software Engineering: A Suevey. 25th Hawaii International Conference on System Sciences, Vol.2, pp. 577566. 
Johnson, D.; Johnson, R. (1999). Learning together and alone: Cooperative, Competitive, and Individualistic Learning (5th ed.), Boston: Allyn \& Bacon.

Johnson, D.; Johnson,T.; Smith, k. (1998). Active Learning: Cooperation in the College Classroom. Esina, MN: Interaction Book Company.

Kanev, K.; Kimura, S.; Orr, T. (2009). A Framework for Collaborative Learning in Dynamic Group Environments. International Journal of Distance Education Technologies, Vol.7.Issue 1, pp. 58-77.

Kirkwood, K. (2010) The SNAP Platform: Social Networking for Academic Purposes. Campus wide Information Systems, Vol.27, No.3, pp. 118-126, emerald Group Publishing Limited.

Kreijns, K.; Kirschner, P.; Jochems, W. (2003). Identifying the Pitfalls for Social Interaction in Computer-Supported Collaborative Learning: A Review of the Research. Computers in Human Behavior, Vol.19, pp. 335-353.

Laister, J.; Kober, S. (2002). Social Aspects of Collaborative Learning in Virtual Learning Environments. Proceedings of the Networked Learning 2002 Conference.

Law, N.; Wong, E. (2003). Developmental Trajectory in Knowledge Building: An Investigation. In Wasson, B.; Hoppe, U. Dsigning for Changes. Kluwer Academic Publishers, Dordrecht, pp. 57-66.

Lin, Q.; Zhang, L.; Ding, W.; Wang, W.; Neo, K.; Gay,R. (2010). 3D Collaborative Virtual Environment Based E-Learning Systems. International Journal of Applied Systemic Studies. Vol.3, No.2, pp. 211-226

Liang, J. (2010). A Web-Based Collaborative Design Architecture for Developing Immersive Virtual Reality Driving Platform. International Journal of Computer Integrated Manufacturing, Vol.23, No.10, (October 2010), pp. 876-892.

Liebregt,M. (2005). Collaborative Virtual in Education. Proceedings of the the Second Twente Conference on IT, Enschede, 21 January.

Lymna,F. (1981). The Responsive Classroom Discussion. In Anderson,A. Mainstreaming Digest. College Park. MD; University of Maryland College of Education.

Manseur, R. (2005). Virtual Reality in Science and Engineering Education. Proceedings of the Frontiers in Education Conference.

McConnell,D. ( 1994) Implementing Computer Supported Coperative Learning. London:Kogan Page. Limited.

McInnerney, J.; Roberts, T. (2004). Online Learning Social Interaction and the Creation of a Sense of Community. Educational Technology and Society, Vol. 7, No.3, pp. 73-81.

Millis, B.; Cottell, P. (1998). Cooperative Learning for Higher Education Faculty. American Council on Education, series on Higher Education. The Oryx Press, Phoenix, AZ.

Monahan,T.; McArdle, G.; Bertolotto, M. (2008). Virtual Reality for Collaborative Learning. Computers \& Education, Vol. 50, Issue 4, (May 2008), pp. 1339-1353.

Montoya, M.; Massey, A.; Lockwood, N. (2011). 3D Collaborative Virtual Environments: Exploring the Link between Collaborative Behaviors and Team Performance.

Decision Sciences, Vol.42, Issue 2, (May 2011), pp. 451-476.

Morrison, D.; Collins, A. (1996). Epistemic Fluency and Constructivist Learning Experiments. In B. Wilson (Ed.) Constructivist Learning Environments, pp. 107-119. Englewood Cliffs: Educational Technology Press.

Moshman,D. (1982). Exogenous, Endogenous, and Dialectical Constructivism. Development Review, Vol.2, pp.371-384. 
Nagy, A. (2005). The Impact of E-Learning, in: Bruck, P.A.; Buchholz, A.; Karssen, Z.; Zerfass, A. (Eds.). E-Content: technologies and Perspectives for the European Market. Berlin: Springer- Verlag, pp. 79-96.

Oliver, R.; McLoughlin, C. (1999). Curriculum and Learning Resources Issues arising from the Use of Web-Based Course Support Systems. International Journal of Educational Telecommunications, Vol. 5, No.4, pp. 419-436.

Osborne, A. (1963). Applied Imagination (3rd ed.). New York: Scribner's

Peffers,K.; Bloom,S. (1999). Internet-Bsed Innovations for Teaching IS Course: The State of Adoption. Journal of Information Technology Theory and Applications, Vol.1, No.1, pp167-172.

Peter, S.; Bacon, E.; Dastbaz, M.(2010). Adaptable, Personalized E-Leaening Incorpration Learning Styles. Campus Wide Information Systems, Vol.27, No.2, , pp.91-100, Emerald Group Publishing Limited.

Ravonscroft, A.; Matheson,M. (2002).Developing and Evaluating Games for Collaborative ELearning. Journal of Computer Assisted Learning, Vol.18, Issue 1 (March 2002), pp.93-101.

Redfern, S.; Galway, N. (2002).Collaborative Virtual Environments to Support Communication and Community in Internet-Based Distance Education. Journal of Information Technology Education., Vol.1,No.3, pp.201-211.

Ryan, J.; O'Sullivan,C.; Bell,C.; Mooney,R. (2004). A Virtual Reality Electrocardiography Teaschnig Tool. Proceedings of the Second International Conference in Biomedical Engineering, pp. 250-253.

Seely Brown, J.; Adler, R. P. (2008). Minds on Fire: Open Education, the Long Tail, and Learning 2.0. Educause Review, January/February 2008, pp. 16-32.

Selinger,M. (1999). The Role of the Techer/Moderator in Virtual Learning Environments. Unpiblished Manuscript, University of Warwick,UK.

Sharan, S.; Sharan, Y. (1976). Small Group Teaching. Englewood Cliffs, NJ: Educational Technology Publications.

Sharan, Y.: Sharan, S. (1992). Expanding Cooperative Learning through Group Investigation. New York: Columbia University.

Sung, R.; Ritchie, J.; Robinson, G.; Day, P.; Corney, J.; Lim, T. (2009). Automated Design Process Modeling and Analysis Using Immersive Virtual Reality. Computer-Aided Design, Vol.41, Issue 12, (December 2009), pp. 1082-1094.

Sweller, j. (1988). Cognitive Load During Problem Solving: Effects on Learning. Cognitive Science, Vol. 12, No. 29, pp. 257-285.

Tavangarian, D.; Leypold, M.; Nolting, K.; Roser, M. (2004). Is E-Learning the Solution for Individual Learning?, Journal of E-Learning, Vol.12, No.4, pp. 15-24.

Van der Linden., Renshaw (Eds.). (2001).Dialogic Learning. Dordrecht: Kluwer Academic Publishers.

Wolf, B.; Burleson, W.; Arroyo, I. ; Dragon, T.; Cooper, D.; Picard, W. (2009). Affect-Aware Tutors: Recognizing and Responding to Student Affect. International Journal of Learning Technology, Vol.4, No.3/4 (November 2009), pp. 68-81.

Young, A. (1997). Mentoring, Modeling, Moitoring, Motivating: Response to Students' Ungraded Writing as Academic Conversation. In Sorcinelli, M.; Elbow,P. (Eds). WEriting to Learn: Strategies for Assigning and Responding to Writing Across Disciplines. 
Zhang, J.; Zhao, L.; Nunamaker, J. (2004). Can E-Learning Replace Classroom Learning?. Communication of the ACM, Vol.47, No. 5, pp. 74-79.

Zhou, D.; Zhang, Z.; Zhong, S.; Xie, P. (2008).The Design of Software Architecture for ELearning Platforms. In Pan, Z. (Ed), Edutainment, LNCS, pp. 32-40. 


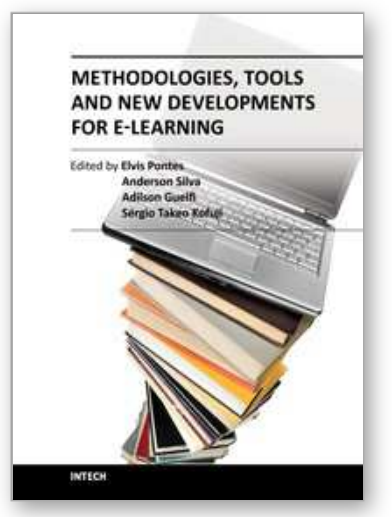

\author{
Methodologies, Tools and New Developments for E-Learning \\ Edited by Dr. Elvis Pontes
}

ISBN 978-953-51-0029-4

Hard cover, 332 pages

Publisher InTech

Published online 03, February, 2012

Published in print edition February, 2012

With the resources provided by communication technologies, E-learning has been employed in multiple universities, as well as in wide range of training centers and schools. This book presents a structured collection of chapters, dealing with the subject and stressing the importance of E-learning. It shows the evolution of Elearning, with discussion about tools, methodologies, improvements and new possibilities for long-distance learning. The book is divided into three sections and their respective chapters refer to three macro areas. The first section of the book covers methodologies and tools applied for E-learning, considering collaborative methodologies and specific environments. The second section is about E-learning assessment, highlighting studies about E-learning features and evaluations for different methodologies. The last section deals with the new developments in E-learning, emphasizing subjects like knowledge building in virtual environments, new proposals for architectures in tutoring systems, and case studies.

\title{
How to reference
}

In order to correctly reference this scholarly work, feel free to copy and paste the following:

Michael K. Badawy (2012). Collaborative E-Learning: Towards Designing an Innovative Architecture for an Educational Virtual Environment, Methodologies, Tools and New Developments for E-Learning, Dr. Elvis Pontes (Ed.), ISBN: 978-953-51-0029-4, InTech, Available from:

http://www.intechopen.com/books/methodologies-tools-and-new-developments-for-e-learning/-collaborative-elearning-towards-designing-an-innovative-architecture-for-an-educational-virtual-en

\section{INTECH}

open science | open minds

\section{InTech Europe}

University Campus STeP Ri

Slavka Krautzeka 83/A

51000 Rijeka, Croatia

Phone: +385 (51) 770447

Fax: +385 (51) 686166

www.intechopen.com

\section{InTech China}

Unit 405, Office Block, Hotel Equatorial Shanghai

No.65, Yan An Road (West), Shanghai, 200040, China

中国上海市延安西路65号上海国际贵都大饭店办公楼405单元

Phone: +86-21-62489820

Fax: $+86-21-62489821$ 
(C) 2012 The Author(s). Licensee IntechOpen. This is an open access article distributed under the terms of the Creative Commons Attribution 3.0 License, which permits unrestricted use, distribution, and reproduction in any medium, provided the original work is properly cited. 